\title{
IMPLANTAÇÃO DE UM SISTEMA DE INFORMAÇÃO DE OUVIDORIA EM UMA INSTITUIÇÃO DE ENSINO DE NÍVEL SUPERIOR
}

\author{
Andréa Cristina Marques de Araújo1 \\ Luis Borges Gouveia²
}

\begin{abstract}
Resumo
$\mathrm{Na}$ atual sociedade da Informação e do Conhecimento, que se caracteriza principalmente através da revolução tecnológica e acesso às informações, as organizações têm de lidar com cidadãos mais exigentes e informados de seus direitos. Nesse contexto, os Serviços de Ouvidorias ganham destaque, uma vez que a excelência no atendimento torna-se fundamental. Como apoio às Ouvidorias, os sistemas de Informação são essenciais para subsidiar um processo decisório de alta qualidade, proporcionando vantagens através da integração entre setores e troca de informação. Dessa forma, o objetivo deste trabalho, fundamentado nos pressupostos teóricos básicos de Sistemas de Informação, é descrever o sistema de Ouvidoria desenvolvido em uma instituição de Ensino Superior em Belém do Pará. A pesquisa apresenta os principais aspectos e relatórios desenvolvidos para suporte da gestão no nível operacional e gerencial da IES, aumentando assim a qualidade do serviço prestado e melhorando $o$ atendimento aos clientes da empresa em estudo.
\end{abstract}

Palavras-chave: Ouvidoria. Tomada de Decisão. Sistemas de Informação. Estudo de Caso.

1 Bacharel em Administração - UNAMA; Especialista em Sistemas de Informação nas Organizações - CESUPA; Mestre em Ciência da Computação - UFSC; Doutoranda em Ciência da Informação - Universidade Fernando Pessoa - Porto/Portugal; Registro na ABO (Associação Brasileira de Ouvidores) n 1084/2014; Certificação em Ouvidoria - $n^{\circ}$ de Registro 832-1 - Associação Brasileira de Ouvidores - Secção Santa Catarina. (andreacristinamaraujo@ gmail.com.)

2 Professor Catedrático da Faculdade de Ciência e Tecnologia da Universidade Fernando Pessoa - Porto/Portugal. Phd in Computer Science, University of Lancaster, UK. MSc. em Engenharia Eletrônica e de Computadores, FEUP, PT. Licenciatura em Informática, Matemáticas Aplicadas. Coordenador do Programa de Doutoramento Ciência da Informação, Universidade Fernando Pessoa - PT. (Imbg@ufp.edu.pt) 


\begin{abstract}
In today's Information and Knowledge Society, characterized primarily through technological revolution and access to information, organizations have to deal with more demanding and informed citizens of their rights. In this context, the Ombudsman Services are highlighted, since excellence in service is essential. In support of Ombudsman's Offices, information systems are essential to support high-quality decision-making processes, providing advantages through cross-sector integration and information exchange. Thus, the objective of this work, based on the basic theoretical assumptions of Information Systems, is to describe the Ombudsman system developed at a Higher Education institution in Belém do Pará. The research presents the main aspects and reports developed to support management at the operational and managerial level of the IES, thus increasing the quality of the service provided and improving the service to the clients of the company under study.
\end{abstract}

Keywords: Ombudsman. Decision Making. Information Systems. Case Study. 


\section{INTRODUÇÃO}

A Sociedade da Informação e do Conhecimento se caracteriza pela Revolução Tecnológica e o acesso às informações através da internet. Os cidadãos estão muito mais exigentes e informados a respeito de seus direitos. Por isso as empresas estão investindo mais em ferramentas de gestão que visam à melhoria da qualidade em atendimento e serviços.

Nesse contexto, o sistema de informação torna-se extremamente necessário para apoiar as tomadas de decisões e atividades existentes nos diversos setores e funções da organização, proporcionando vantagens através da integração entre setores e troca de informações.

ARAÚJO (2002) coloca que a informação é fator-chave para subsidiar o processo decisório em uma organização. Os sistemas de informação são, portanto, ferramentas estratégicas que vão transformar os dados das atividades rotineiras em informações, subsidiando com qualidade e no tempo certo a tomada de decisão.

Dessa forma, este trabalho apresenta como questão norteadora analisar como as organizações, mais especificamente os setores de Ouvidoria, podem utilizar os sistemas de informação de forma mais eficiente a fim de subsidiar um processo decisório de alta qualidade, melhorando a gestão organizacional.

\section{SISTEMAS DE INFORMAÇÃO E PROCESSO DECISÓRIO}

Segundo ARAÚJO (2002), as organizações têm como base no desempenho de suas atividades um conjunto de tomadas de decisões. As decisões ocorrem em todos os níveis hierárquicos. Tanto na rotina diária quanto na alta administração acontecem tomadas de decisão e, para isso, as organizações utilizam-se das informações.

As informações para as operações do cotidiano permitem à organização levar adiante suas atividades de rotina, o dia a dia do negócio, o que ocorre no nível operacional. As decisões no nível estratégico possibilitam aos gestores tomar decisões que mudam a organização ou seus métodos empresariais (FREITAS; KLADIS, 1995). Na figura abaixo representamos o fluxo das rotinas e decisões em uma organização.

\section{FIGURA 1 - Fluxo Decisório}

Fonte: Freitas e Kladis (1995, p. 08)

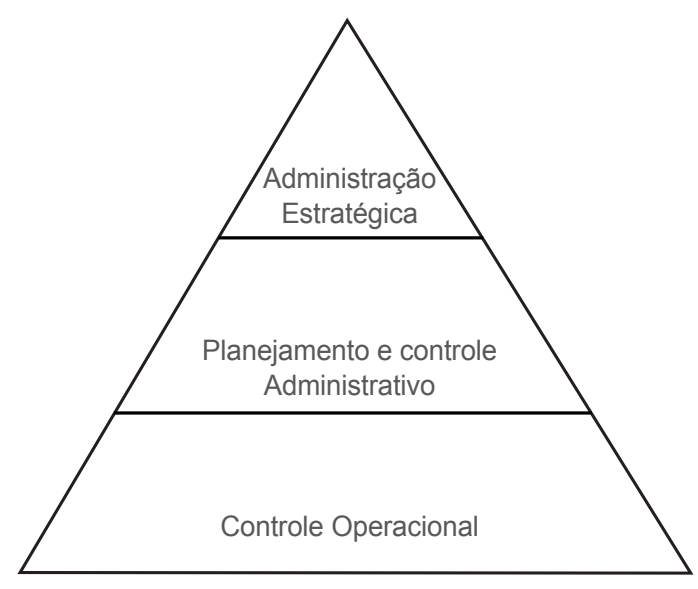

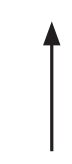

Abrangência e importância das decisões

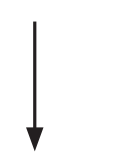


O sucesso da organização está, portanto, na capacidade de ser ágil e transformar informação em oportunidade. O conhecimento passa a ser o recurso principal, e o grande desafio para que se sobressaia na era da informação é motivar seus elementos humanos a, através da própria iniciativa e de suas habilidades, transformar em meios de ação seus conhecimentos (ARAÚJO, 2002).

\section{ESTUDO DE CASO - O SISTEMA DE OUVIDORIA}

O sistema de informação objeto desta pesquisa foi implementado em 2014, quando da reestruturação da Ouvidoria institucional, tendo como foco um papel mais atuante do setor e o advento de ferramenta de gestão para a IES.

A Ouvidoria recebe as demandas exclusivamente através do sistema online disponibilizado na home page da instituição e, caso o demandante solicite momento presencial, é feito o agendamento do horário para o atendimento. As demais áreas da IES acessam o sistema através da rede interna, cujo processo já faz parte da cultura institucional. As demandas são encaminhadas para manifestação e conhecimento ao setor responsável, que responde à Ouvidoria pelo próprio sistema. Todas as demandas obedecem ao caráter de sigilo.

O sistema apresenta relatórios operacionais, com o nível de detalhamento que o cotidiano institucional demanda, e também relatórios gerenciais, subsidiando assim a gestão da média e da alta direção.

Como demandantes, tendo em vista o universo de sujeitos do contexto, foram classificados quatro tipos: aluno, público externo, funcionários e professores. O sistema gera um relatório estratificando a quantidade absoluta de demandas registradas por cada sujeito, bem como o percentual equivalente. A Tabela 1 apresenta os tipos de demandantes, bem como seu peso total nas demandas reportadas.

\section{TABELA 1 - Tipos de Demandantes}

\begin{tabular}{|l|l|l|}
\multicolumn{2}{c}{ DEMANDA } \\
\hline DESCRIÇÃO & QUANTIDADE & $\%$ \\
\hline Aluno & 18 & 78,26 \\
\hline Externo & 5 & 21,74 \\
\hline Funcionário & 0 & 0 \\
\hline Professor & 0 & 0 \\
\hline TOTAL & 23 & 100 \\
\hline
\end{tabular}

Fonte: Sistema de Ouvidoria (2018, online) 
Quanto ao tipo da demanda, foi definido que o sistema deveria receber cinco categorias: elogio, sugestão, reclamação, denúncia e informação. A Tabela 2 apresenta os tipos diferenciados e a distribuição das demandas recebidas.

\section{TABELA 2 - Tipos de Demandas}

\begin{tabular}{|l|l|l|}
\hline \multicolumn{2}{l}{ TIPOS } \\
\hline DESCRIÇÃO & QUANTIDADE & $\%$ \\
\hline Elogio & 15 & 3,77 \\
\hline Sugestão & 34 & 8,54 \\
\hline Reclamação & 199 & 50,00 \\
\hline Denúncia & 14 & 3,52 \\
\hline Informação & 136 & 34,17 \\
\hline TOTAL & 398 & 100 \\
\hline
\end{tabular}

Fonte: Sistema de Ouvidoria (2018, online)

Outra necessidade identificada para os relatórios gerenciais foi a estratificação por assunto. Foi criada uma lista inicial de tópicos dinâmica, que é atualizada à medida que novos assuntos recorrentes são registrados pelos demandantes. Exemplo disso foi a inclusão do tópico Vestibular, que inicialmente não constava na listagem, mas que, após um período com o registro de dez demandas no sistema em um mês, foi incluído na lista de opções (Figura 2).

FIGURA 2 - Print de Tela

do Sistema Online

Ouvidoria com o

Detalhamento

dos Assuntos

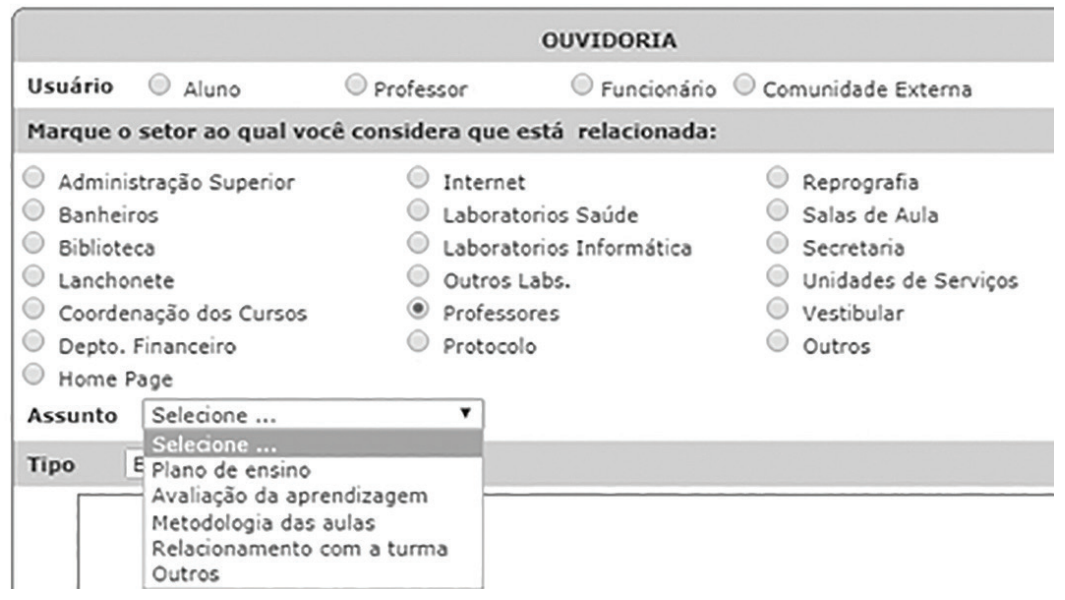

Fonte: Sistema de Ouvidoria (2018, online) 
Assim o usuário, quando for registrar a demanda, precisa escolher um dos tópicos da lista de assuntos. Caso não tenha a opção que ele deseja, pode escolher o assunto genérico "outros". Existe a possibilidade de ele marcar equivocadamente ou não ter escolhido a opção mais adequada para os relatórios da Ouvidoria. Caso isso aconteça, o Ouvidor tem a possibilidade de alterar no sistema a escolha do assunto. O sistema gera relatório consolidando as demandas por assunto (setor), o que possibilita informações gerenciais importantes para a gestão superior (Tabela 3).

\section{TABELA 3 - Consolidação das Demandas por Setor/Assunto}

\begin{tabular}{|c|c|c|}
\hline \multicolumn{3}{|c|}{ RECLAMAÇÃO POR SETOR } \\
\hline DESCRIÇÃO & QUANTIDADE & $\%$ \\
\hline Coordenação dos Cursos & 1 & 16,67 \\
\hline Unidades de Serviços & 1 & 16,67 \\
\hline Depto. Financeiro & 3 & 50,00 \\
\hline Outros & 1 & 16,66 \\
\hline TOTAL & 6 & 100 \\
\hline
\end{tabular}

Fonte: Sistema de Ouvidoria (2018, online)

Outra informação gerencial apresentada pelo sistema é quanto à resolução das demandas. Como modo operacional de trabalho, a Ouvidoria especificou o prazo de atendimento de até 5 dias úteis. Para avaliar o desempenho de atendimento, o sistema gera informações quanto às demandas que foram resolvidas no prazo e fora do prazo, conforme tabela abaixo (Tabela 4).

\section{TABELA 4 - Situação de Atendimento das Demandas}

\begin{tabular}{|l|l|l|l|l|}
\hline \multicolumn{5}{|l}{ RESOLVIDOS } \\
\hline DESCRIÇÃO & NO PRAZO & $\%$ & FORA DO PRAZO & $\%$ \\
\hline Reclamação & 6 & 100,00 & 0 & 0 \\
\hline Denúncia & 0 & 0 & 0 & 0 \\
\hline Informação & 11 & 91,67 & 1 & 8,33 \\
\hline TOTAL & 17 & & 1 & \\
\hline $\begin{array}{l}\text { Denúncia - Prazo de atendimento de até 3 dias úteis } \\
\text { Reclamação e Informação - Prazo de atendimento de até 5 dias úteis }\end{array}$
\end{tabular}

Fonte: Sistema de Ouvidoria (2018, online) 


\section{CONCLUSÃO}

A Ouvidoria atua em uma organização buscando a melhoria de sua gestão e a satisfação do cliente. Escutar o cliente é extremamente importante, pois, conhecendo suas necessidades, as organizações terão medidas para melhorar continuamente.

O estudo de caso apresentado demonstrou a implementação do novo sistema de informação da Ouvidoria em uma instituição de ensino superior na cidade de Belém do Pará. O desenvolvimento do novo sistema teve como princípios conceituais e balizadores o foco na geração de informações adequadas a cada nível hierárquico onde ocorre a tomada de decisão.

FREITAS e KLADIS (1995) explicitam que cada nível organizacional possui suas particularidades, definidas e aplicadas de forma a facilitar e viabilizar o funcionamento da tomada de decisão. Os diferentes níveis demandam, portanto, necessidades diferenciadas de informação, especificidades às quais os sistemas de informação não podem deixar de atender.

Identificar a necessidade de informação adequada às características do nível hierárquico em que acontece o processo decisório e utilizar essa informação de forma cada vez mais competitiva é vital para que a organização garanta sua sobrevivência no mercado.

\section{REFERÊNCIAS}

ABO NACIONAL. Disponível em: http://www.abonacional.org.br. Acesso em: 6 out. 2012.

ARAÚJO, Andréa Cristina Marques de. A Administração na Era da Informação: Uma abordagem teórica sobre a importância da informação e do seu gerenciamento para sucesso estratégico das organizações. Rio de Janeiro: Editora Papel Virtual, 2002.

; GOUVEIA, Luis Borges. Os digitais nas instituições de ensino superior. Rio de Janeiro: Publit, 2017.

ASSOCIAÇÃO BRASILEIRA DE OUVIDORES/OMBUDSMAN. ABO. Site Geral. Disponível em: www.abonacional. org.br. Acesso em: 15 jul. 2012.

BORGES, Maria Alice Guimarães. A compreensão da sociedade da informação. Ciência da Informação, Brasília, DF, v. 29, n. 3, p. 25-32, set./dez. 2000. Disponível em: <http://revista.ibict.br/ciinf/index.php/ciinf/article/view/214>. Acesso em: 23 abr. 2013.

FREITAS, H; KLADIS, C. M. O processo decisório: Modelos e dificuldades. Revista Decidir, ano II, n. 8, p. 30-34, mar. 1995

LAUDON, Kenneth C.; LAUDON, Jane Price. Gerenciamento de sistemas de informação. 3. ed. Rio de Janeiro: LTC, 2001.

Sistemas de informação gerenciais. 7. ed. São Paulo: Pearson Education do Brasil, 2007.

STAIR, Ralph M.; REYNOLDS, George W. Princípios de sistemas de informação: uma abordagem gerencial. 2. ed. Rio de Janeiro: LTC, 1998. 